\title{
Unanticipated population structure of European grayling in its northern distribution: implications for conservation prioritization Akarapong Swatdipong*1, Anti Vasemägi ${ }^{1}$, Mikko T Koskinen ${ }^{2}$, Jorma Piironen $^{3}$ and Craig R Primmer ${ }^{1}$
}

\author{
Address: ${ }^{1}$ Department of Biology, University of Turku, Turku, Finland, ${ }^{2}$ Finnzymes Diagnostics, Espoo, Finland and ${ }^{3}$ Finnish Game and Fisheries \\ Research Institute, Joensuu, Finland \\ Email: Akarapong Swatdipong* - akarapong.swatdipong@utu.fi; Anti Vasemägi - anti.vasemagi@utu.fi; \\ Mikko T Koskinen - mikko.koskinen@finnzymes.fi; Jorma Piironen - jorma.piironen@rktl.fi; Craig R Primmer - craig.primmer@utu.fi \\ * Corresponding author
}

Published: 30 March 2009

Frontiers in Zoology 2009, 6:6 doi:10.1186/1742-9994-6-6
Received: 24 October 2008

Accepted: 30 March 2009

This article is available from: http://www.frontiersinzoology.com/content/6/1/6

(C) 2009 Swatdipong et al; licensee BioMed Central Ltd.

This is an Open Access article distributed under the terms of the Creative Commons Attribution License (http://creativecommons.org/licenses/by/2.0), which permits unrestricted use, distribution, and reproduction in any medium, provided the original work is properly cited.

\begin{abstract}
Background: The European grayling (Thymallus thymallus) is a salmonid fish native to Europe, with a distribution ranging from England and France to the Ural Mountains of north-western Russia. The majority of grayling populations inhabit freshwater rivers and lakes but some populations also occupy brackish water in northern parts of the Baltic Sea. Previous population genetic studies have demonstrated that grayling populations in Finland, Estonia and Russia belong to a single mitochondrial lineage and exhibit high levels of differentiation even at a small geographic scale. As a result, we predicted that grayling populations should not cluster regionally. Despite the extensive amount of genetic research that has been carried out on grayling, comprehensive national-level information on population structure of grayling in Northern Europe is still lacking. Yet this is the level at which populations are currently managed.
\end{abstract}

Results: We found unanticipated population structure of grayling clustering into three groups largely corresponding to the northern, Baltic and south-eastern geographic areas of Finland using 13 microsatellite loci. We also found a high level of genetic differentiation among the groups and moderate to high differentiation within the groups. This combined with low variability strongly indicates that genetic drift and limited migration have a major impact on grayling population structure. An allele size permutation test indicated that mutations at microsatellite loci have not significantly contributed to genetic differentiation among the three Finnish groups. However, at the European scale, mutations had significantly contributed to population differentiation.

Conclusion: This research provides novel genetic information on European grayling in its northern distribution range and has clear implications for supporting country-scale conservation efforts. Specifically, the strong between population divergence observed indicates that single populations should generally be recognized as separate management units. We also introduced an alternative prioritization strategy for population conservation based on the evaluation of the relative roles of different evolutionary forces shaping the gene pools. We envision that the proposed approach to categorize populations for conservation will be a useful tool for wildlife researchers and conservationists working on a diverse range of organisms. 


\section{Background}

The European grayling, Thymallus thymallus, is a salmonid fish highly appreciated by recreational anglers. It is native to Europe with a distribution from England and France to the Ural Mountains of north-western Russia. It can inhabit stream, riverine or lacustrine habitats and show large phenotypic differences in gill raker number, body size, weight at first spawning and fecundity [1]. While grayling occur mostly in freshwater habitats, some populations also occupy brackish water in the northern parts of the Baltic Sea.

Population genetic structure of the European grayling has been studied rather extensively across its natural distribution, but particularly in central Europe, using both mitochondrial sequences and microsatellite markers [2-7]. In central and northern Europe, the population structure is represented by four major lineages with (lineage) contact zones in Germany [8] and northern Sweden and Finland [9]. In northern Europe, two major lineages have been described $(3.1 \%$ and $1.1 \%$ divergences using mtDNA PCR-RFLP and 529-bp of ND5 sequence, respectively; [9]). One lineage that almost exclusively inhabits Sweden and Norway most likely originated from a central European refugium while grayling in Finland, Estonia and north-western Russia belong to a different mitochondrial lineage originating most likely from an eastern European refugium [9]. Northern European grayling have been studied also at a very small geographic scale [10]. In lake Saimaa, Finland, Koskinen et al. [11] found evidence of severely limited gene flow among populations separated by just tens of kilometres.

Despite the quite extensive amount of genetic research that has been carried out on grayling, detailed nationallevel information of grayling population structure in Northern Europe is lacking. Yet, this is the level at which populations are currently managed. Based on the previous work, we expect that grayling populations in Northern Europe exhibit high genetic differentiation even at a small geographic scale (prediction 1) and possibly show just a relatively weak isolation-by-distance signal as genetic drift should be the dominant evolutionary force compared to migration. However, as Finnish grayling populations belong to a single mitochondrial lineage on one hand and show extremely low gene flow on the other, we do not expect that grayling in Finland exhibit further genetic clustering or grouping (prediction 2).

In this study, the major objective was to provide genetic information from a geographically representative set of populations to assist country-scale conservation of grayling in Finland. We analyzed grayling sampled throughout Finland in order to test the predictions based on the knowledge from previous population genetic studies, using a panel of 13 microsatellite markers. For compara- tive purposes, we analyzed grayling populations from Russia, Sweden, Norway and Germany. We also categorized and prioritized populations according to predominant evolutionary forces, providing useful information for the development of a scientifically justified nationalscale conservation strategy of grayling in Finland.

\section{Materials and methods Fish samples}

Grayling were sampled from 15 locations within Finland, between 1996 to 2001 (figure 1a). Fin clips were stored in 95\% ethanol. DNA was extracted using a salt-based method described by Aljanabi and Martinez [12]. Information on population status, location and geographic coordinates are given in table 1.

\section{Microsatellite data}

Initially, seventeen microsatellite markers employed by Koskinen et al. [13] were re-screened using 16 individuals representing a number of populations and two loci were then excluded (BFRO9 and BFRO16) due to low levels of polymorphism. Forward primers were labeled fluorescently with FAM for BFRO4, BFRO5, BFRO7, BFRO10 and BFRO13; VIC for BFRO15, BFRO17, BFRO18 and Ogo 2; NED for BFRO12, Cocl23 and Str85INRA; and PET for BFRO11, ONE2, and Str73INRA. Primer concentrations were optimized for co-amplification of 15 loci in a single multiplex PCR and the amplicons were size-measured in a single capillary electrophoresis. The $6.25 \mu \mathrm{l}$ multiplex PCR reaction consisted of ca. $125 \mathrm{ng}$ of template DNA, 1× multiplex PCR master mix (Qiagen) and 0.015 to $1.915 \mu \mathrm{M}$ of each primer. Exact concentrations of primers are provided in the supplementary material [see Additional file 1]. Amplifications were carried out in a PTC100 thermal cycler (MJ Research) with an initial heat-activation at $95^{\circ} \mathrm{C}$ for 15 minutes ( $\mathrm{min}$ ) followed by 37 cycles of denaturation at $94^{\circ} \mathrm{C}$ for 30 seconds (sec), annealing at $55^{\circ} \mathrm{C}$ for $90 \mathrm{sec}$ and extension at $72^{\circ} \mathrm{C}$ for $60 \mathrm{sec}$. The PCR was terminated after $30 \mathrm{~min}$ of final extension at $60^{\circ} \mathrm{C}$.

PCR products were diluted, denatured and then electrophoresed on an ABI Prism 3130xl genetic analyzer (Applied Biosystems/Hitachi) along with GeneScan 600 LIZ size standard (Applied Biosystems). DNA fragments were genotyped using GeneMapper 4.0 (Applied Biosystems). All genotypes were manually inspected and examples of electropherograms are shown in the supplementary material [see Additional file 2]. Besides the 15 newly genotyped Finnish populations, previously published data [13] from seven populations within Finland and six populations from Russia, Sweden, Norway and Germany were included (table 1). Three of the previously published Finnish populations (102 individuals in total) were re-genotyped in this study to enable calibration of allele sizes. 


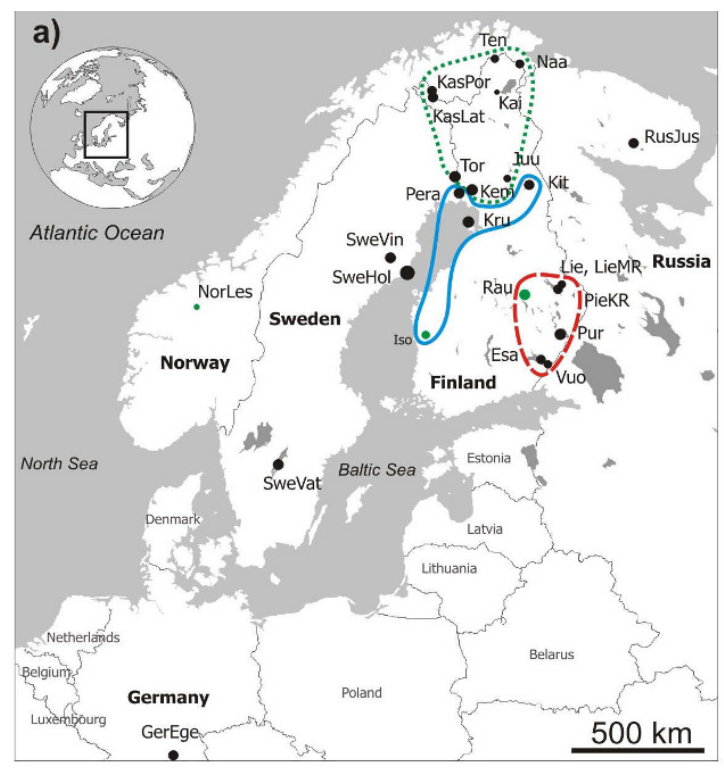

b)

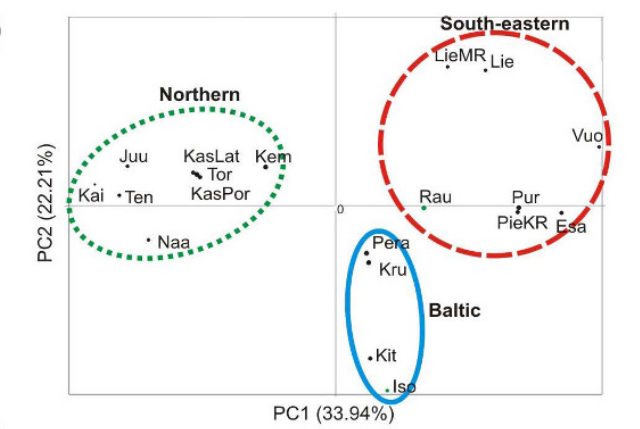

c)

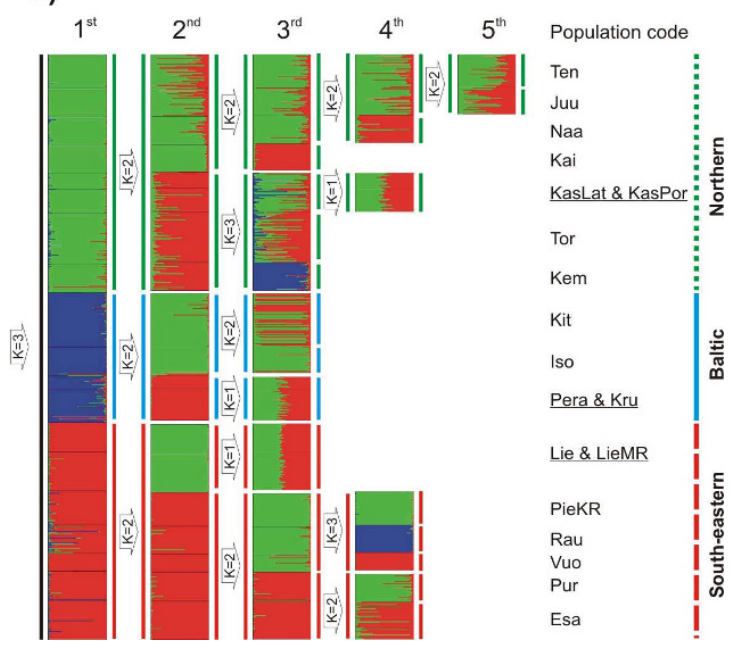

Figure I

Grayling sampling locations and analyses of population structure based on I3-microsatellite loci. Populations are coded as in table I. a) A map indicating sampling locations. Three population groups are indicated with different color lines corresponding to the three clusters identified using PCA. Dot sizes are proportioned to allelic richness of each population. Black and green dots stand for indigenous and supplementary stocked populations, respectively. b) Principal Component Analysis of Finnish grayling populations based on microsatellite allele frequencies. c) Individual clustering as inferred by series of hierarchical partitioning using Structure. Each individual is represented by a thin horizontal line pooled into K-colored blocks indicating individual's membership fractioned in K clusters. Black horizontal lines separate individuals from different sampling sites. 
Table I: Locations and status of grayling populations in the study.

\begin{tabular}{|c|c|c|c|c|c|c|}
\hline \multicolumn{5}{|c|}{ Location } & \multirow[b]{2}{*}{ Source status } & \multirow[b]{2}{*}{ Sampling site } \\
\hline Water system & Code & Region & \multicolumn{2}{|c|}{ Co-ordinates } & & \\
\hline Tenojoki & Ten & Finland. $\mathrm{N}$ & $6954^{\prime} 40.97 " \mathrm{~N}$ & $2702^{\prime} 48.36^{\prime \prime} \mathrm{E}$ & indigenous & river \\
\hline Näätämöjoki & $\mathrm{Naa}$ & Finland. $\mathrm{N}$ & $6942^{\prime} 22.98 " \mathrm{~N}$ & 29 00' 05.76"E & indigenous & river \\
\hline Kaitamo (Inari) & Kai & Finland. $\mathrm{N}$ & $6847^{\prime} \quad 12.94 " \mathrm{~N}$ & 26 58' 39.83"E & indigenous & lake \\
\hline Käsivarsi, Poroeno & KasPor & Finland. $\mathrm{N}$ & $6858^{\prime} 46.33^{\prime \prime} \mathrm{N}$ & 22 04' 36.37"E & indigenous & river \\
\hline Käsivarsi, Lätäseno & KasLat & Finland. $\mathrm{N}$ & $6850^{\prime} 00.00 " \mathrm{~N}$ & 22 II' 52.34"E & indigenous & river \\
\hline Tornionjoki & Tor & Finland. $\mathrm{N}$ & $6630^{\prime} 00.00^{\prime \prime} \mathrm{N}$ & $2344^{\prime}$ I $5.16^{\prime \prime} \mathrm{E}$ & indigenous & river \\
\hline Juujarvi & Juu & Finland. $\mathrm{N}$ & $6622^{\prime} 41.59 " \mathrm{~N}$ & 27 I6' 50.43"E & indigenous & river \\
\hline Kemijoki & Kem & Finland. $\mathrm{N}$ & $6606^{\prime} 40.75^{\prime \prime} \mathrm{N}$ & 24 5I' 58.33"E & indigenous & river \\
\hline Kitkajärvi & Kit & Finland. $\mathrm{N}$ & 66 I0'02.44"N & $2842^{\prime} 32.28 " \mathrm{E}$ & indigenous & lake \\
\hline Perämeri & Pera & Finland. $\mathrm{N}$ & 6601 ' 35.99"N & $2400^{\prime} 47.04 " \mathrm{E}$ & indigenous & sea \\
\hline Ulkokrunnit & Kru & Finland. Bothnian bay & $6512^{\prime} 23.62 " \mathrm{~N}$ & 2435 ' I4.3।"E & indigenous & sea \\
\hline Lieksanjoki & Lie & Finland. SE & $6318^{\prime} 43.44^{\prime \prime} \mathrm{N}$ & $3002^{\prime}$ I $6.60 " \mathrm{E}$ & indigenous & river \\
\hline Lieksanjoki & LieMR & Finland. SE & $6318^{\prime} 43.44^{\prime \prime} \mathrm{N}$ & 30 02' I6.60"E & indigenous & river \\
\hline Pielinen & PieKR & Finland. SE & 63 I' $2^{\prime} 45.27 " \mathrm{~N}$ & $2946^{\prime}$ । $9.54^{\prime \prime} \mathrm{E}$ & indigenous & lake \\
\hline Rauanjoki & $\mathrm{Rau}$ & Finland. SE & $6307^{\prime} 17.52 " \mathrm{~N}$ & 27 46' 44.04"E & hatchery & river \\
\hline Isojoki & Iso & Finland. SW & $6206^{\prime} 36.58 " \mathrm{~N}$ & $2157^{\prime} 21.28 " \mathrm{E}$ & mixed & river \\
\hline Puruvesi & Pur & Finland. SE & $6157^{\prime} 07.38^{\prime \prime} \mathrm{N}$ & $2937^{\prime}$ ' $9.222^{\prime \prime} \mathrm{E}$ & indigenous & lake \\
\hline Etelä-Saimaa & Esa & Finland. SE & $6119^{\prime} 32.54 " \mathrm{~N}$ & $2823^{\prime} 22.52 " \mathrm{E}$ & indigenous & lake \\
\hline Vuoksi river & Vuo & Finland. SE & $6110^{\prime} 17.28 " \mathrm{~N}$ & 28 46' 44.43"E & indigenous & river $^{\mathrm{a}}$ \\
\hline Juzija river & RusJus & Russia. Kola peninsula & $6658^{\prime} 13.80^{\prime \prime} \mathrm{N}$ & $3620^{\prime} 48.86 " \mathrm{E}$ & indigenous & river \\
\hline Vindelälven & SweVin & Sweden. E & 64 II' 58.34"N & $1942^{\prime} 07.67 " \mathrm{E}$ & indigenous & river \\
\hline Holmön & SweHol & Sweden. Bothnian bay & $6347^{\prime} 59.63 " \mathrm{~N}$ & $205 I^{\prime} 28.83 " \mathrm{E}$ & indigenous & sea \\
\hline Vättern & SweVat & Sweden. S & $5817^{\prime} 41.85^{\prime \prime} \mathrm{N}$ & I4 28' 39.98"E & indigenous & lake \\
\hline Lesjaskogsvatn & NorLes & Norway. S & $6212^{\prime} 02.67 " \mathrm{~N}$ & $825^{\prime}$ I5.।I"E & introduced & lake \\
\hline Eger river & GerEge & Germany. Central & $4927^{\prime}$ II.74"N & II 04' $21.96 " E$ & indigenous & river \\
\hline
\end{tabular}

a The outlet of lake Saimaa.

\section{Statistical analyses}

Microsatellite diversity, Hardy-Weinberg and genotypic linkage equilibrium

GenePop 3.4 [14] was initially employed to screen for deviations from Hardy-Weinberg (H-W) equilibrium and two loci (BFRO4 and ONE2) were excluded due to highly significant heterozygote deficiency $(P<0.0001)$ in several populations, likely indicating the presence of null alleles. Thus, the final dataset comprised 13 loci. Because some of the sampled populations can be affected by stocking with individuals of non-native origin (table 1), Structure 2.2 [15] was used to identify individuals that represented genotypes highly unlikely to be native to the sampled population. In total, 15 individuals belonging to four populations (1-6 individuals per population) were identified with highly unlikely genotypes compared to the rest of the samples and these putatively non-natives were excluded from further analysis. The final dataset consisted of 936 individuals from 25 populations.

Allele number and allelic richness were estimated using FSTAT 2.9.3.2 [16]. Observed and expected heterozygosity were measured using Microsatellite Toolkit 3.1 [17]. Deviations from Hardy-Weinberg equilibrium and genotypic linkage equilibrium were calculated using Genepop 3.4. For the combination of separate tests across loci (H-W test) or locus pairs (linkage equilibrium test), Fisher's procedure was applied [18]. Throughout the study, sequential Bonferroni corrections [19] were performed to correct for multiple testing.

\section{Genetic differentiation and relationships between populations}

Inter-population genetic divergence was calculated using the multilocus $F_{\mathrm{ST}}$ estimator of Weir \& Cockerham [20] with FSTAT 2.9.3.2. Population differentiation was tested as genic differentiation for all population pairs using Genepop 3.4. The genetic relationship among populations was examined by Principal Component Analysis (PCA), based on allele frequencies, using PCAGEN 1.2 [21]. Population clustering was performed with a hierarchical partitioning approach as previously employed by Vähä et al. [22], using Structure 2.2 based on the delta K method [23] calculated from 20 replicates of $\ln \operatorname{Pr}(\mathrm{X} \mid \mathrm{K})$ under each K. Different run lengths were used (burn-in 20 000 to 80000 iterations and, after that, data were collected for 20000 to 80000 iterations) to achieve stable results.

\section{Analysis of molecular variance}

To estimate the amount of molecular variation associated with different sets of population groupings, hierarchical analysis of molecular variance (AMOVA) was performed 
using Arlequin 3.1 [24]. By this analysis, genetic variation residing within each alternative population clustering was measured. Three alternative scenarios were tested based on the PCA results: grouping 1 (three population groups corresponding to northern, Baltic and south-eastern populations), grouping 2 (northern vs Baltic and south-eastern groups combined) and grouping 3 (Pera and Kru were re-located into the south-eastern group. Other populations were as in grouping 1).

\section{Mantel test}

An association between the geographic distance and genetic divergence matrices was examined using the Mantel test implemented in the GenAlEx 6.1 package [25] supported by multiple regression and a correlation extension procedure [26]. The statistical significance of the parameter estimates was obtained via 9999 permutations. Interpopulation geographic distances were directly calculated from latitude and longitude data using the great circle distance method [27]. $F_{\mathrm{ST}} /\left(1-F_{\mathrm{ST}}\right)$ was used as a measurement of genetic divergence in the Mantel test while the geographic distance matrix was used as ln transformed as well as raw distance [28]. For detecting IBD within the three population groups with higher statistical power, a socalled "pooled within-stratum" approach was applied to the Mantel test as suggested by Smouse, PE (personal communication). Briefly, matrices from each of three population groups were permuted using GenAlex 6.1 to generate 999 values of the sum of permuted XY (spXY). The spXY from each population group were resampled using PopTool 2.7 [29] to yield 1000 random combinations of "pooled" spXY $[\operatorname{sum}(X Y)=\operatorname{sumA}(X Y)+\operatorname{sumB}(X Y)$ $+\operatorname{sum} C(X Y) ; \mathrm{A}, \mathrm{B}$ and $\mathrm{C}$ stand for each population group]. Later, "pooled" sum $\left(\mathrm{X}^{2}\right)$ and $\operatorname{sum}\left(\mathrm{Y}^{2}\right)$ were calculated accordingly. One-thousand pooled $\mathrm{R}_{\mathrm{XY}}$ were subsequently obtained as $R_{X Y}=\frac{s p X Y}{\sqrt{\left[\operatorname{sum}\left(X^{2}\right)\right]\left[\operatorname{sum}\left(Y^{2}\right)\right]}}$. The pooled $\mathrm{R}_{\mathrm{XY}}$ were ranked and the corresponding P-value was calculated.

\section{Allele size permutation test}

To test whether stepwise-like mutations have significantly contributed to genetic differentiation between populations, the allele size randomization test [30] was employed using SPAGeDi 1.2 [31]. Theoretically, $R_{\mathrm{ST}}$ is analogous to $F_{\mathrm{ST}}$, where $R_{\mathrm{ST}}$ is a stepwise mutation based measurement of genetic differentiation taking into account the variance of microsatellite allele size [32]. When the contribution of mutations to genetic differentiation is not significant as compared with genetic drift and migration $F_{\mathrm{ST}}$ and $R_{\mathrm{ST}}$ are expected to have similar values. If stepwise-like mutations have significantly contributed to the differentiation $R_{\mathrm{ST}}$ is expected to be larger than $F_{\mathrm{ST}}$. In the allele size permutation test, the distribution of $R_{\mathrm{ST}}$ values from 10000 permutations $\left(\mathrm{p} R_{\mathrm{ST}}\right)$ was compared to observed $R_{\mathrm{ST}}$. The test of allele size permutation was performed at three different hierarchical levels; among population groups within Finland as identified by PCA and Structure analyses, among countries and among 25 grayling populations.

\section{Population prioritization for conservation}

In order to rank populations in terms of their conservation priority, Contrib $1.20[33,34]$ was used to calculate both the diversity (allelic richness) and the differentiation (related to Nei's $D_{\mathrm{ST}}$ and $G_{\mathrm{ST}}$ ) components of each population. These parameters are relative measurements and are evaluated as the contribution of each population to total allelic richness (contribution to total allelic richness; CTR) pooled from all populations. Thus, negative values indicate that the diversity or the differentiation of a population is lower than the mean of the whole dataset. For prioritizing grayling populations within Finland, foreign populations were excluded from the analysis in order to avoid the underestimation of the differentiation component within Finnish populations. Two Finnish populations (Iso and Rau) were also excluded because of their mixed origin, from hatchery stocking of non-native fish [35], which would artificially increase their diversity component compared to indigenous gene pools.

\section{Results \\ Microsatellite diversity, Hardy-Weinberg and genotypic linkage equilibrium}

The average number of alleles per locus varied from 1.6 (Kai) to 5.4 (Tor) while the average allelic richness ranged from 1.6 (Kai) to 4.6 (SweHol; table 2). Observed and expected heterozygosity were lowest in Kai $\left(\mathrm{H}_{\mathrm{o}}=0.21 ; \mathrm{H}_{\mathrm{e}}=0.20\right)$ and highest in SweHol $\left(\mathrm{H}_{\mathrm{o}}=0.60 ; \mathrm{H}_{e}=0.63\right)$. No deviation from Hardy-Weinberg equilibrium was observed for any locus after the sequential Bonferroni correction $(k=13)$. Genotypic linkage equilibrium tests suggested linkage disequilibrium $(\mathrm{P}<0.0001)$ between five population-locus pairs: BFRO7-BFRO13 in Esa; BFRO11-BFRO13 and BFRO13BFRO18 in Kit; BFRO12-Cocl3 and BFRO15-Cocl23 in Juu. However, as each of these five linkage disequilibrium occurred only in a single population and none involved the same two loci, these loci are likely not in physical linkage. Beside these five locus pairs, no deviation from genotypic linkage equilibrium was observed after the sequential Bonferroni correction $(k=78 ; \mathrm{P}=0.0015-0.9999)$. Therefore, for subsequent analyses, all loci were assumed to have independent segregation of alleles.

\section{Level of differentiation and genetic relationships between populations}

When all 25 populations were included in the PCA, three populations (GerEge, Norles and SweVat) were very dis- 
Table 2: Locations, sample sizes, microsatellite diversity estimates and Hardy-Weinberg $(\mathrm{H}-\mathrm{W})$ equilibrium test for the grayling.

\begin{tabular}{|c|c|c|c|c|c|c|}
\hline \multicolumn{2}{|c|}{ Location } & \multirow[b]{2}{*}{ Sample size } & \multicolumn{3}{|c|}{ Microsatellite diversitya } & \multirow[b]{2}{*}{$\mathrm{H}-\mathrm{W}^{\mathrm{b}}$} \\
\hline Water system & Code & & $A_{r}$ & $\mathrm{H}_{\circ}$ & $\mathrm{H}_{\mathrm{e}}$ & \\
\hline Tenojoki & Tenc & 42 & $2.68(I-5)$ & 0.27 & 0.31 & 0.1941 \\
\hline Näätämöjoki & $\mathrm{Naa}$ & 35 & $2.79(I-7)$ & 0.33 & 0.36 & 0.2232 \\
\hline Kaitamo (Inarijoki) & Kai & 34 & $1.56(I-3)$ & 0.21 & 0.20 & 0.9783 \\
\hline Käsivarsi, Poroeno & KasPor & 20 & $3.10(1-7)$ & 0.31 & 0.33 & 0.0436 \\
\hline Käsivarsi, Lätäseno & KasLatc & 29 & $3.22(I-6)$ & 0.36 & 0.35 & 0.9356 \\
\hline Tornionjoki & Tor $^{c}$ & 63 & $3.64(I-7)$ & 0.36 & 0.37 & 0.2143 \\
\hline Juujarvi & Juu & 35 & $2.47(I-5)$ & 0.29 & 0.27 & $0.666 I$ \\
\hline Kemijoki & Kem & 35 & $3.63(2-6)$ & 0.47 & 0.47 & 0.5617 \\
\hline Kitkajärvi & Kit & 67 & $3.20(1-6)$ & 0.46 & 0.49 & 0.0597 \\
\hline Perämeri & Pera & 17 & $3.44(1-6)$ & 0.47 & 0.47 & 0.9974 \\
\hline Ulkokrunnit & Kruc & 40 & $3.55(1-6)$ & 0.48 & 0.48 & 0.1999 \\
\hline Lieksanjoki & Lie & 36 & $2.44(I-5)$ & 0.39 & 0.36 & 0.7229 \\
\hline Lieksanjoki & LieMRc & 48 & $2.58(I-4)$ & 0.35 & 0.33 & 0.9241 \\
\hline Pielinen & PieKRc & 42 & $3.02(I-5)$ & 0.47 & 0.47 & 0.0615 \\
\hline Rauanjoki & Rau & 35 & $3.43(1-6)$ & 0.52 & 0.52 & 0.0039 \\
\hline Isojoki & Iso & 36 & $2.61(1-5)$ & 0.41 & 0.44 & 0.1002 \\
\hline Puruvesi & Pur & 36 & $3.55(2-5)$ & 0.52 & 0.53 & 0.0056 \\
\hline Etelä-Saimaa & $\mathrm{Esa}^{\mathrm{c}}$ & 48 & $2.98(I-5)$ & 0.49 & 0.47 & 0.1214 \\
\hline Vuoksi river & Vuo & 22 & $2.5 I(I-4)$ & 0.36 & 0.34 & 0.6244 \\
\hline Juzija river & RusJus ${ }^{c}$ & 32 & $3.12(1-6)$ & $0.4 I$ & 0.42 & 0.8362 \\
\hline Vindelälven & SweVinc & 38 & $3.37(I-6)$ & 0.46 & 0.47 & 0.4106 \\
\hline Holmön & SweHolc & 34 & $4.55(2-7)$ & 0.60 & 0.63 & 0.3041 \\
\hline Vättern & SweVatc & 45 & $3.32(1-8)$ & 0.43 & 0.45 & 0.0170 \\
\hline Lesjaskogsvatn & NorLesc & 30 & $1.81(1-4)$ & 0.22 & 0.24 & 0.4477 \\
\hline Eger river & GerEgec $^{c}$ & 37 & $3.23(1-6)$ & 0.41 & 0.41 & 0.0353 \\
\hline
\end{tabular}

a allelic richness (based on 16 individual re-samplings; $A_{r}$ ), observed heterozygosity $\left(H_{0}\right)$ and expected heterozygosity $\left(H_{e}\right)$ within a population across the 13 microsatellite loci. Numbers within parentheses indicate range for $A_{r}$. ${ }^{\circ}$-value for $\mathrm{H}$-W equilibrium test across 13 loci, no populations remained significant following the sequential Bonferroni correction. c Data taken from Koskinen et al. [13].

tinct compared to the rest along the first principal component axis (data not shown). This deep divergence corresponds to two mtDNA lineages described by Koskinen et al. [9]. When only 19 Finnish populations were included in the analyses, populations clustered into three separate groups: 'northern', 'Baltic' and 'south-eastern' (figure 1b). The 'northern' group was the most homogeneous and distinct from the latter two groups. The 'northern' group included eight populations, three of them (Ten, Naa and Kai) inhabiting rivers flowing north to the Barents Sea basin, four of them (KasLat, KasPor, Tor and Kem) to the Baltic Sea basin and Juu to the White Sea basin. In the 'south-eastern' group, both populations from Lieksanjoki (Lie and LieMR) were clustered closely to each other but showed some distance from the remaining south-eastern members. The third, 'Baltic', group was separated from the two other population groups along the second PCA axis and consisted of four populations, including Kit that is close to Iso. This was surprising, as Kit is currently $174 \mathrm{~km}$ from the Baltic Sea and $556 \mathrm{~km}$ from Iso. Additionally, the two Swedish populations (SweHol and SweVin) from the Baltic coastline initially clustered with the 'Baltic' group and the Russian population from the Kola Peninsula (RusJus) clustered with the 'northern' group (data not shown).

Similar to the PCA results, population clustering analysis using the program Structure without prior information about population of origin of individuals initially distinguished three main groups of Finnish grayling corresponding to 'northern', 'Baltic' and 'south-eastern' groups (figure 1c). After the second round of partitioning, six separate clusters were identified. The third partitioning revealed eleven clusters. Kai, Tor, Kem, Kit and Iso were separated from the remaining samples, while the pairs of Pera-Kru and Lie-LieMR exhibited no further separation. After the fourth and fifth partitioning, the northern and south-eastern groups were divided into seven and six clusters, respectively. In total, the hierarchical partitioning series produced sixteen separate clusters corresponding very well to the number of geographic sampling sites (eighteen Finnish sampling sites in total).

The global $F_{\mathrm{ST}}$ across all 25 populations was 0.342 indicating a very high level of differentiation among individual grayling populations. Within Finland, the global $F_{\mathrm{ST}}$ was 
0.294 and the $F_{\mathrm{ST}}$ within the three population clusters was $0.145,0.146$ and 0.256 for the northern, Baltic and southeastern group, respectively. Pairwise $F_{\mathrm{ST}}$ among populations is detailed in the supplementary material [see Additional file 3]. The test of genic differentiation indicated that all pairs of populations were significantly different to each other $(\mathrm{P}<0.001)$, except for KasPor-KasLat and PeraKru ( $P=0.259$ and 0.427 , respectively).

The hierarchical analysis of molecular variance revealed that the proportion of total genetic variance due to differences between groups was highest for grouping $1\left(F_{\mathrm{CT}}=\right.$ 0.191). The two alternative hierarchical groupings explained smaller proportions of variation $\left(F_{\mathrm{CT}}=0.183\right.$ and 0.160 for grouping 2 and 3, respectively).

\section{Mantel test}

A significant isolation-by-distance (IBD) signal was observed

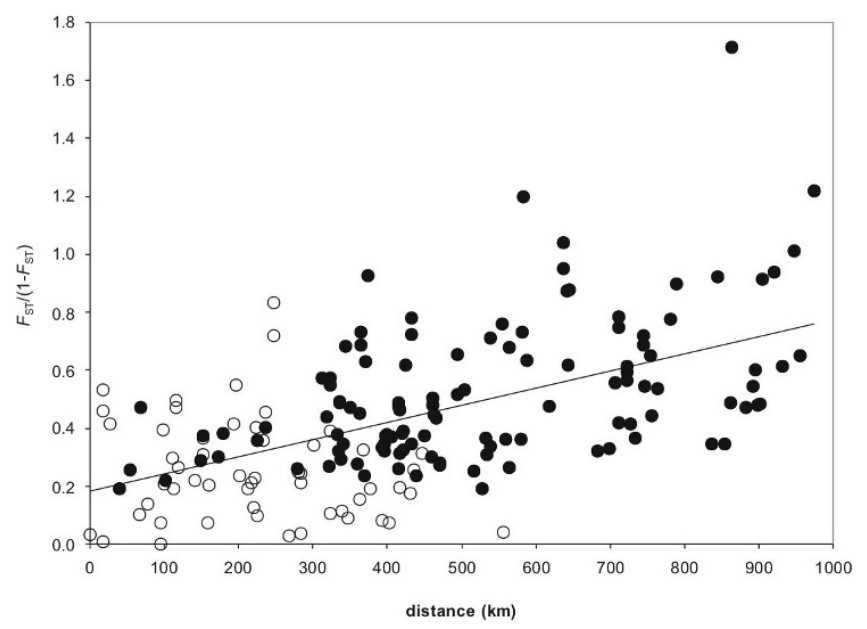

Figure 2

Mantel test indicating the observed isolation-by-distance signal driven by among-group comparisons, but not within-group. Trend line is for all comparisons. Solid and open dots are for the among- and within-group comparisons, respectively.

when all Finnish populations were included in the analysis $\left(\mathrm{R}_{\mathrm{XY}}=0.558 ; \mathrm{P}<0.001\right.$; figure 2$)$. However, non-significant IBD patterns were observed within each of the three Finnish groups $\left(\mathrm{R}_{\mathrm{XY}}=-0.008,0.233\right.$ and 0.314 ; all associated $\mathrm{P}>$ 0.05; within northern, Baltic and south-eastern groups, respectively). In addition, pooled within-group comparisons did not result in significant IBD signal $\left(\mathrm{R}_{\mathrm{XY}}=-0.153, \mathrm{P}>\right.$ 0.05). The Mantel test using ln distance provided the same conclusion as employing the raw geographic distance.

\section{Allele size permutation test}

The allele size permutation test indicated that mutations at microsatellite loci did not significantly contribute to genetic differentiation among the three Finnish groups compared to genetic drift and migration. At the European scale, the permutation test indicated that mutations had significantly contributed to population differentiation (global multilocus $F_{\mathrm{ST}}$ and $R_{\mathrm{ST}}$ among 25 populations = 0.342 and 0.476 , respectively; $\mathrm{P}<0.001$ ). In the among five countries comparison, the observed multilocus $R_{\mathrm{ST}}$ also fell well above the upper limit of the $95 \%$ confidence interval (CI) of the null distribution of $\mathrm{p} R_{\mathrm{ST}}$ (global multilocus $F_{\mathrm{ST}}$ and $R_{\mathrm{ST}}$ among five countries $=0.230$ and 0.492 , respectively; $\mathrm{P}<0.001$, figure 3 ). Pairwise comparisons further indicated that $R_{\mathrm{ST}}>\mathrm{p} R_{\mathrm{ST}}$ when comparing Finland with Norway or Germany. The permutation test suggested that $R_{\mathrm{ST}}$ was still significantly larger than $\mathrm{p} R_{\mathrm{ST}}$ when comparing Finland with Russia but the 95\% CI of $\mathrm{p} R_{\mathrm{ST}}$ were not very different from the observed $R_{\mathrm{ST}}$ (global multilocus $F_{\mathrm{ST}}$ and $R_{\mathrm{ST}}=0.129$ and 0.186 , respectively; $\mathrm{P}=$ $0.044)$. However, $R_{\mathrm{ST}}$ was not significantly larger than $\mathrm{p} R_{\mathrm{ST}}$ when comparing Finland with Sweden (global multilocus $F_{\mathrm{ST}}$ and $R_{\mathrm{ST}}=0.124$ and 0.062 , respectively; $\mathrm{P}=$ $0.883)$. When the SweHol sample from the Baltic sea was excluded from the analyses because it essentially belongs to the same Baltic group as Kru, Pera, Kit and Iso $R_{\mathrm{ST}}$ was still very similar to $\mathrm{p} R_{\mathrm{ST}}$ indicating the predominant role of genetic drift and migration over mutation when comparing Finnish and Swedish populations.

\section{Population prioritization and categorization for conservation}

By plotting diversity and differentiation components calculated using the Contrib program, the following categories of populations were identified: 1) high diversityhigh differentiation group, 2) high diversity-low differentiation group; 3) low diversity-high differentiation group and 4) low diversity-low differentiation group (figure 4a). Arguably, these categories largely reflect the relative roles of genetic drift and gene flow affecting the grayling populations and therefore can be useful for developing genetically justified conservation strategies for populations. The first category (high diversity-high differentiation group) contains seven populations that have high levels of diversity and exhibit differentiation higher than average. The second category (high diversitylow differentiation group) contains three populations that have a higher amount of diversity than average while the level of differentiation is rather low compared to the other populations. The third category (low diversity-high differentiation group) contains five populations that exhibit a lower amount of diversity than average and at the same time shows an increased differentiation component. The fourth category (low diversity-low differentiation group) contains two populations that exhibit somewhat lower genetic diversity as well as reduced differentiation compared to the average. For comparative purpose, the Contrib results are presented in a more traditional way by combining the diversity and differentiation components (figure 4b). 


\section{Discussion}

\section{Unanticipated population structuring}

In accordance with other population genetic studies in European grayling $[3,8,11,13,36,37]$ we found a generally high level of differentiation between the majority of populations. However, in contrast to our expectations and previous studies using microsatellites and mitochondrial DNA, we identified unanticipated signals of regional clustering of grayling populations in Finland. Such grouping was evident using both PCA and individual multi-locus genotype based analysis and further supported by analysis of molecular variance (AMOVA). The three population groups identified roughly correspond to separate geographic areas: the northern, Baltic and south-eastern regions. Nevertheless, all these three identified groups belong to a single European grayling mitochondrial lineage [9] and thus could be considered as one evolutionarily significant unit based on criteria sensu Moritz [38]. One of the reasons why the previous studies $[9,13]$ of grayling in Finland did not detect such clustering is probably due to the low number of populations analyzed from the region. We observed high genetic differentiation between three population groups and moderate to high differentiation within the northern, Baltic and south-eastern groups. Significant IBD signal was identified when all Finnish popu- lations were analyzed together while no significant relationship between genetic and geographic distances was found among populations within the three groups and pooled within-group comparisons. Thus, the overall IBD signal most likely derives from the structuring of Finnish populations into three groups rather than from concurrent gene flow between neighboring populations, even though the power to detect significant IBD signal was lower for within group comparisons. This is in accordance with other studies in European grayling demonstrating that inter-population dispersal is extremely limited even among neighboring populations $[11,39,40]$.

Rather surprisingly, several different types of analyses strongly indicated that the Kitkajärvi population (Kit) groups together with the Baltic populations even though this population inhabits an inland lake that is relatively distant from the Baltic Sea $(174 \mathrm{~km})$ and, moreover, currently flows into the White Sea basin. However, it is known that Kitkajärvi (lake Kitka) had postglacially bifurcated outflow; the eastward channel drained into the Baltic sea via the system of Livojärvi (lake Livo) until around 8400 years ago, and the westward channel flowed into the White Sea via Kitkajoki (river Kitka) as it still does [41]. The postglacial colonization of grayling into north-

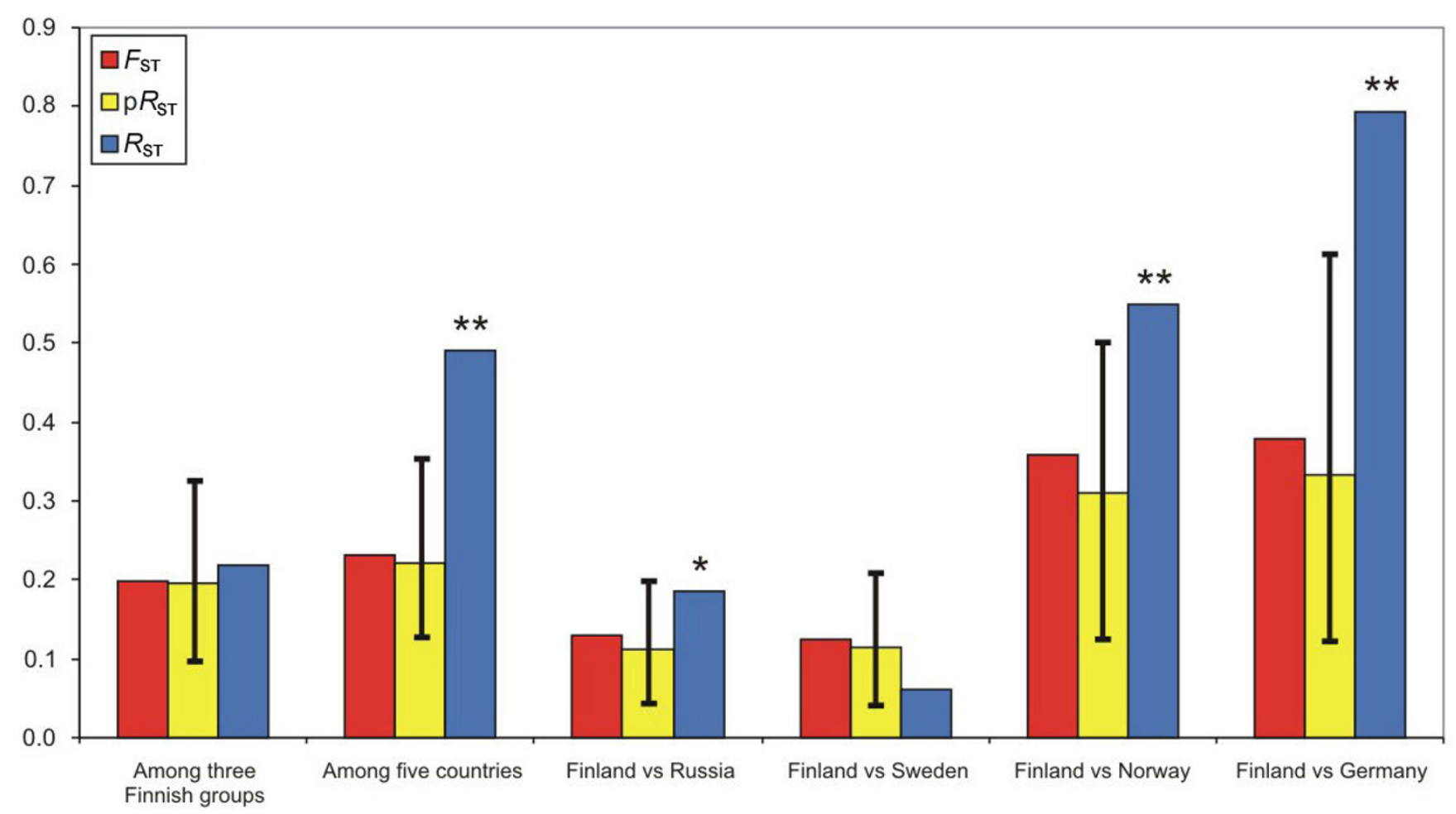

Figure 3

Global $\boldsymbol{F}_{\mathrm{ST}}, \mathrm{p} \boldsymbol{R}_{\mathrm{ST}}$ and $\boldsymbol{R}_{\mathrm{ST}}$ estimated among three Finnish groups and among five countries. The $95 \%$ confidence intervals are given for $\mathrm{p} R_{\mathrm{ST}}$. One or two asterisks are indicated (for $0.0 \mathrm{I} \leq \mathrm{P}<0.05$ or $\mathrm{P}<0.0 \mathrm{I}$, respectively) where global $R_{\mathrm{ST}}$ was significant compared to the null distribution $\mathrm{p} R_{\mathrm{ST}}$. 


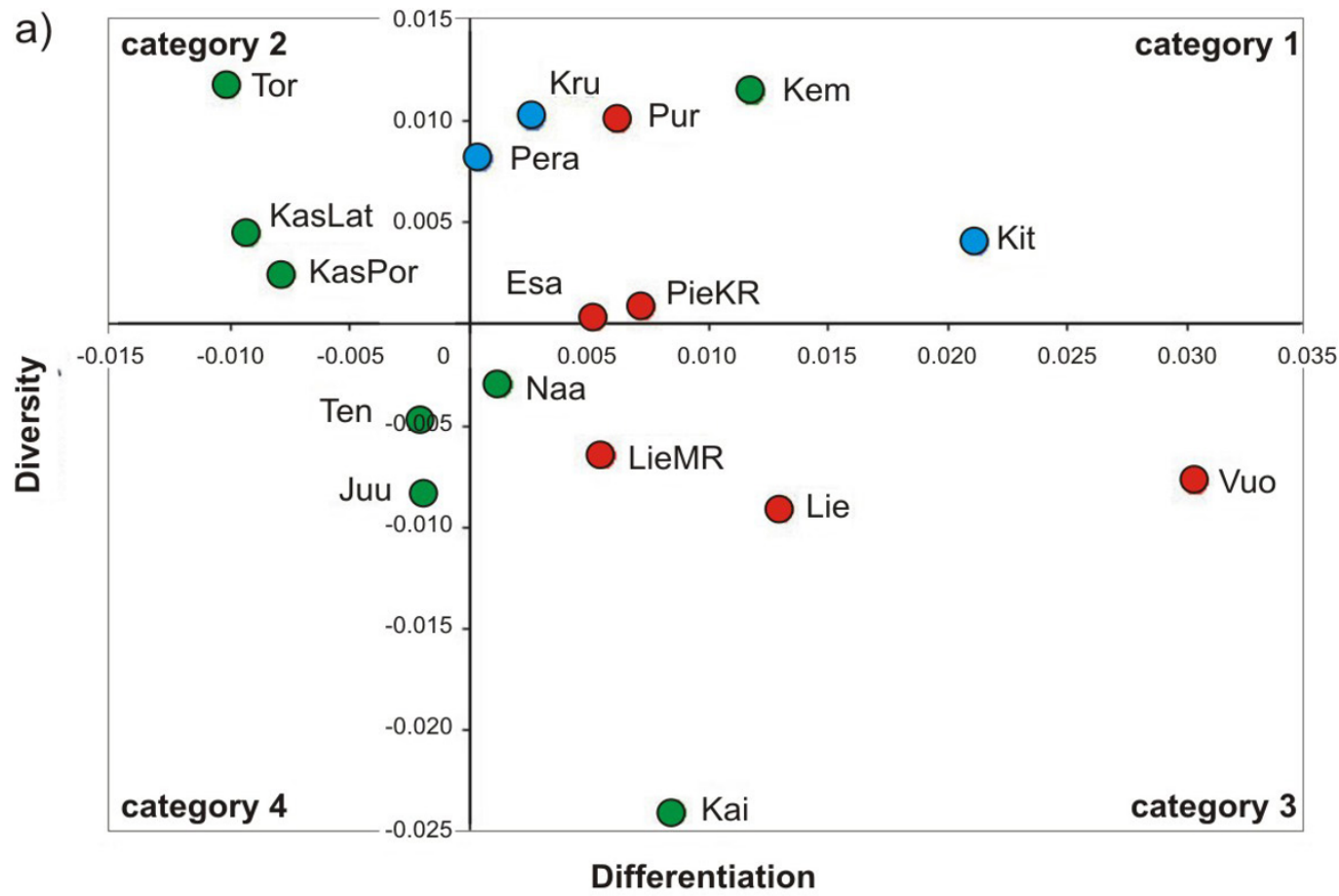

b)

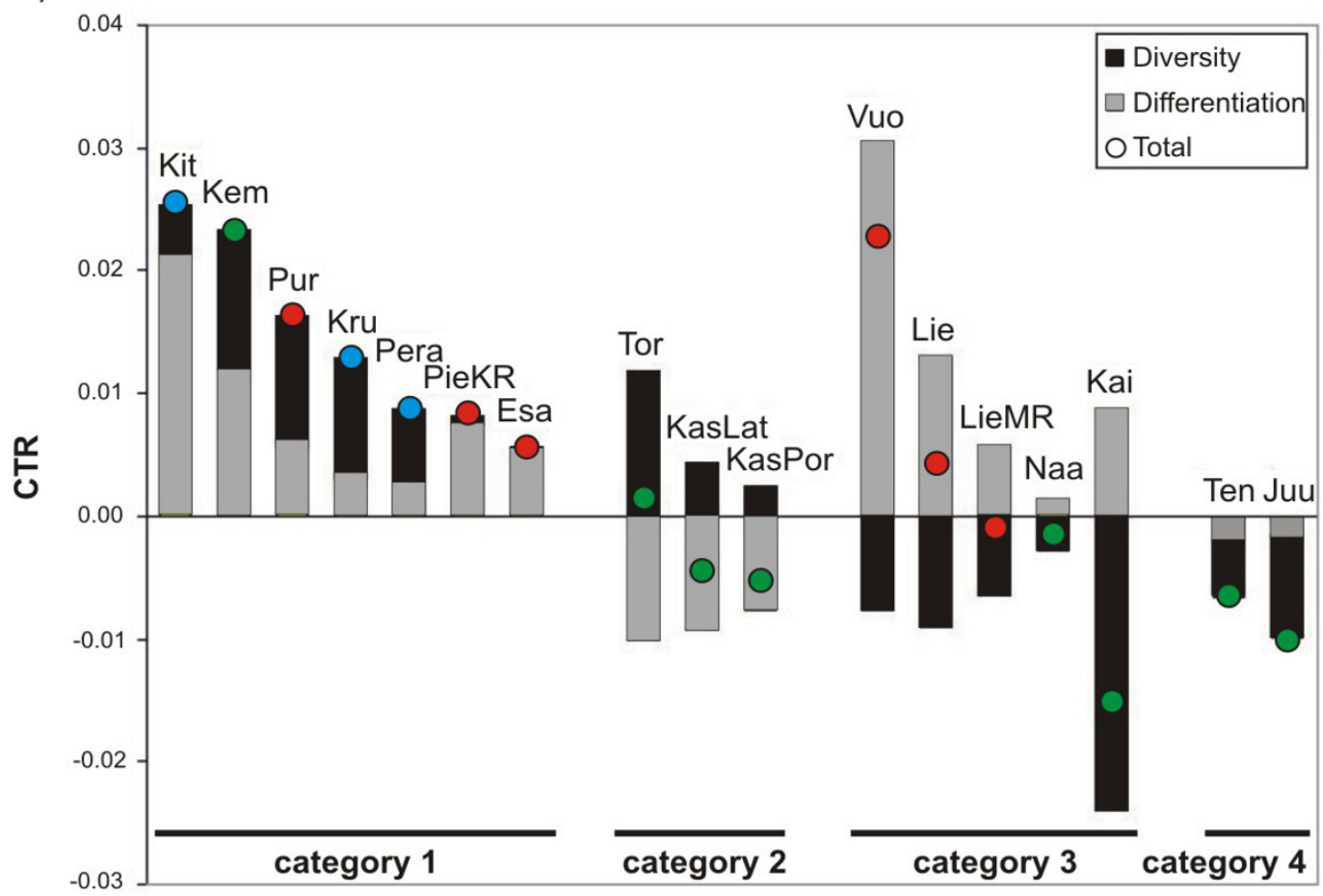

Figure 4

Diversity and differentiation components of 17 Finnish grayling populations. a) A 2D graph representing four different conservation categories of populations. Category I stands for high diversity-high differentiation, category 2 for high diversity-low differentiation, category 3 for low diversity-high differentiation and category 4 for low diversity-low differentiation. b) A bar graph indicating the categories and population prioritization (more important at left). Populations are colored differently according to the PCA and are coded as in table I. 
ern Europe has been estimated to have begun ca. 10500 - 13000 years ago [9] and thus we can hypothesize that the present Kitkajärvi grayling population was established through the historical waterway from the Baltic Sea more than 8400 years ago. An alternative explanation is that there has been stocking activities of Baltic graying into Kitkajärvi, although there is no documented evidence supporting this scenario.

\section{Genetic diversity}

Among salmonid fishes, European grayling is one of the least genetically variable species, exhibiting low diversity even across highly variable markers such as microsatellites. In Atlantic salmon (Salmo salar), brown trout (Salmo trutta), whitefish (Coregonus hoyi) and rainbow trout (Oncorhynchus mykiss), the mean expected heterozygosity measured at microsatellite loci commonly varies from 0.63 to 0.76 (e.g. [4245]) while the mean expected heterozygosity in this study was as low as 0.41 and ranged from 0.20 to 0.63 . Hence, either the effective population size, level of migration or microsatellite mutation rate in European grayling is smaller than in other salmonid populations. When looking at specific populations, NorLes from Norway had extremely low allelic richness $\left(\mathrm{A}_{\mathrm{r}}=1.81\right)$ and low heterozygosity $\left(\mathrm{H}_{e}=0.24\right)$, which is in accordance with the demographic history of the population as it is known that NorLes was most likely established by a small number of individuals in 1880 [10]. However, we found that the natural population (Kai) in Inarijoki flowing to lake Inari showed even lower levels of diversity $\left(A_{r}\right.$ $\left.=1.56, \mathrm{H}_{e}=0.20\right)$. As most of the study populations are from the area that was completely covered by an ice sheet during the last glacial period, it is possible that the low variability of grayling in northern Europe reflects postglacial colonization and subsequent founder effects $[46,47]$. However, the southernmost population from central Germany included in our study showed relatively low levels of variability $\left(\mathrm{A}_{\mathrm{r}}=3.23, \mathrm{H}_{\mathrm{e}}\right.$ $=0.41$ ) and other studies concentrating on the southern distribution range of European grayling have shown low diversity levels $[2,7,8,37,48]$. This strongly indicates that genetic drift and limited migration have a strong impact on diversity and population structure of grayling. However, as there is no estimator of the microsatellite mutation rate available for grayling one cannot exclude the possibility that the mutation rate in European grayling is lower than in other salmonid fishes, although it seems unlikely.

\section{The role of mutations contributing to population differentiation}

Despite the clear separation of the three population groups in Finland there was no evidence that mutations have significantly contributed to the genetic differentiation among these groups. Thus, even though we observed relatively high differentiation between the three population groups, the allele permutation test indicated that patterns of differentiation are mostly driven by genetic drift and low migration rather than accumulation of new mutations. However, the allele size permutation test strongly suggested that mutations significantly contributed to population differentiation on a broader geographic scale.

\section{Population conservation categorization based on the role of different evolutionary forces}

The "central dogma of conservation genetics" is that genetic variability is beneficial and therefore it is often assumed that increasing genetic variability enhances population survival [49]. Another important aspect of prioritizing populations for conservation is their genetic uniqueness measured at the molecular genetic or phenotypic level (e.g. evolutionary distinctiveness [50]). Hence for population conservation, it is relevant to evaluate both of these parameters but considerable controversy exists about the relative weights of diversity and uniqueness components (e.g [51]). Based on the strong clustering of Finnish populations, it is recommendable that national conservation efforts include populations from all three genetically distinct groups. In this study, we used an alternative approach that is still based on examining populations according to diversity and differentiation but instead of simply summing the diversity and uniqueness components based on rather subjective weighting, populations were categorized based on the predominant evolutionary forces acting on them. As a result, this approach is expected to be more objective compared to ranking solely on the summation of diversity and differentiation components based on arbitrary weights without losing crucial information about the relative roles of underlying evolutionary forces. For example, when simply combining diversity and differentiation components sensu Petit et al. [33], it is possible to get similar prioritization ranks for two populations with markedly different demographic histories - a population with low diversity-high differentiation can have a similar priority rank as another population with high diversity-low differentiation. It is clear that the first population could be severely affected by e.g. inbreeding depression while the second population might contain high genetic variability necessary for population survival and long-term evolution.

When examining diversity and differentiation components in grayling populations, we identified four categories where the relative importance of different evolutionary forces (namely drift and migration) varies. These categories are high diversity-high differentiation (category 1), high diversity-low differentiation (category 2), low diversity-high differentiation (category 3) and low diversity-low differentiation (category 4). From the conservation perspective, the populations falling into the high diversity-high differentiation category (e.g. Kit, Kem and Pur; from the Baltic, northern and south-eastern groups, respectively) may be less affected by genetic drift and migration as they represent large isolated populations. This high diversity-high differentiation category has the highest likelihood of containing unique genetic material. Notably, all three Baltic members fall into 
this category and given that grayling populations in the Baltic Sea are likely adapted to the brackish environment, they are hence highly relevant for conservation [52]. Populations that belong to the high diversity-low differentiation category (Tor, KasLat and KasPor) represent relatively large populations where the effect of drift is small, while migration may have some effect on the gene pool. We propose that populations in these two categories represent the top priority for conservation. Populations that belong to the low diversityhigh differentiation category (e.g. Vuo, Lie and Kai) may represent small populations strongly affected by genetic drift. From a conservation genetic perspective, these populations have a lower probability of being able to evolve and survive in the future. Importantly, this does not necessarily mean that these populations cannot adapt to local conditions. For example, it has been shown that even in small grayling populations natural selection can have a predominant role over random genetic drift in affecting the fitness of phenotypic traits [10]. Populations that belong to the low diversity-low differentiation category (Ten and Juu) might be classified as a low conservation priority, as low differentiation reflects their lack of 'uniqueness' compared to other populations and low variability can additionally hinder adaptation in the future. However, it is also important to emphasize that these two populations have both the diversity and differentiation components quite close to the average across all populations. Taken together, the high levels of genetic differentiation observed among grayling populations here, as well as in other studies $[3,4,8,11,37]$ clearly suggests that generally single populations should be the principal unit for conservation and management and thus population intermixing should be avoided. We also recommend using the proposed categorization strategy, taking into account the relative role of different evolutionary forces, as a basis for the conservation of grayling in Finland as well as of other species.

\section{Conclusion}

This research provides genetic information on European grayling in its northern distribution range in order to assist country-scale conservation. We found unanticipated population structure of grayling, clustering into three groups largely corresponding to the northern, Baltic and south-eastern geographic areas of Finland and we recommend that these three groups should be used as the starting point for developing a national grayling conservation strategy. However, as the observed clusters extend beyond the borders of Finland, international co-operation for broader scale conservation management is warranted. We also found high levels of genetic differentiation among the groups and moderate to high differentiation within the groups. Such strong divergence indicates that single grayling populations should generally be recognized as separate management units. We also developed an alternative prioritization strategy in the conservation perspective by categorizing populations based on the evaluation of the relative role of various evolutionary forces affecting the indigenous gene pool. We envision that the proposed population categorization approach could be useful for a diverse range of organisms.

\section{Competing interests}

The authors declare that they have no competing interests.

\section{Authors' contributions}

AS carried out the molecular genetic work, statistical analyses and wrote the first draft of the manuscript. MTK performed genotyping in some populations. JP conducted the majority of the fieldwork. MTK, JP, AV and CRP COdesigned the research theme. AV and CRP were involved in developing later drafts of the manuscript. All authors read and approved the final manuscript.

\section{Additional material}

\section{Additional file 1}

Characteristics of microsatellite loci used in the study. Primer concentration and summary statistics of microsatellite loci.

Click here for file

[http://www.biomedcentral.com/content/supplementary/17429994-6-6-S1.doc]

\section{Additional file 2}

Electropherograms of four individuals, each genotyped at 15 microsatellite loci in a single multiplex polymerase chain reaction. Electropherograms generated by GeneMapper software.

Click here for file

[http://www.biomedcentral.com/content/supplementary/1742-

9994-6-6-S2.jpeg]

\section{Additional file 3}

Pairwise genetic distance as measured with $\mathrm{R}_{S T}$ (above the diagonal) and $\mathrm{F}_{S T}$ (below the diagonal). Pairwise genetic distance of the grayling populations as measured with $\mathrm{R}_{S T}$ and $\mathrm{F}_{S T}$.

Click here for file

[http://www.biomedcentral.com/content/supplementary/17429994-6-6-S3.doc]

\section{Acknowledgements}

We acknowledge anonymous reviewers for their constructive comments. This study was supported by a Royal Thai Scholarship (to AS) and the Academy of Finland (to AV- academic post-doctoral fellowship, and to CP-Centre of Excellence in Evolutionary Genetics and Physiology).

\section{References}

I. Zinov'ev EA: Ecotypes in graylings (thymallidae, salmoniformes). Russian Journal of Ecology 2005, 36:349-353.

2. Susnik S, Snoj A, Dovc P: Microsatellites in grayling (Thymallus thymallus): comparison of two geographically remote populations from the Danubian and Adriatic river basin in Slovenia. Molecular Ecology 1999, 8: I756-I758.

3. Gross R, Kuhn R, Baars M, Schroder W, Stein H, Rottmann O: Genetic differentiation of European grayling populations across the Main, Danube and Elbe drainages in Bavaria. Journal of Fish Biology 200I, 58:264-280. 
4. Susnik S, Snoj A, Dovc P: Evolutionary distinctness of grayling (Thymallus thymallus) inhabiting the Adriatic river system, as based on mtDNA variation. Biological Journal of the Linnean Society 200I, 74:375-385

5. Uiblein F, Jagsch A, Honsig-Erlenburg W, Weiss S: Status, habitat use, and vulnerability of the European grayling in Austrian waters. Journal of Fish Biology 200I, 59:223-247.

6. Duftner N, Koblmuller S, Weiss S, Medgyesy N, Sturmbauer C: The impact of stocking on the genetic structure of European grayling (Thymallus thymallus, Salmonidae) in two alpine rivers. Hydrobiologia 2005, 542:121-129.

7. Gum B, Gross R, Kuehn R: Discriminating the impact of recent human mediated stock transfer from historical gene flow on genetic structure of European grayling Thymallus thymallus L. Journal of Fish Biology 2006, 69: II 5-135.

8. Gum B, Gross R, Kuehn R: Mitochondrial and nuclear DNA phylogeography of European grayling (Thymallus thymallus): evidence for secondary contact zones in central Europe. Molecular Ecology 2005, I 4:1707-1725.

9. Koskinen MT, Ranta E, Piironen J, Veselov A, Titov S, Haugen TO, Nilsson J, Carlstein M, Primmer CR: Genetic lineages and postglacial colonization of grayling (Thymallus thymallus, Salmonidae) in Europe, as revealed by mitochondrial DNA analyses. Molecular Ecology 2000, 9:1609-1624.

10. Koskinen MT, Haugen TO, Primmer CR: Contemporary fisherian life-history evolution in small salmonid populations. Nature 2002, 419:826-830.

II. Koskinen MT, Piironen J, Primmer CR: Interpopulation genetic divergence in European grayling (Thymallus thymallus, Salmonidae) at a microgeographic scale: implications for conservation. Conservation Genetics 200I, 2: I33-143.

12. Aljanabi SM, Martinez I: Universal and rapid salt-extraction of high quality genomic DNA for PCR-based techniques. Nucleic Acids Research 1997, 25:4692-4693.

13. Koskinen MT, Nilsson J, Veselov AJ, Potutkin AG, Ranta E, Primmer CR: Microsatellite data resolve phylogeographic patterns in European grayling, Thymallus thymallus, Salmonidae. Heredity 2002, 88:39|-40I.

14. Raymond M, Rousset F: Genepop (version I.2) - Population genetics software for exact tests and ecumenicism. Journal of Heredity 1995, 86:248-249.

15. Pritchard JK, Stephens M, Donnelly P: Inference of population structure using multilocus genotype data. Genetics 2000, 155:945-959.

16. Goudet J: FSTAT (Version I.2): A computer program to calculate F-statistics. Journal of Heredity 1995, 86:485-486.

17. Park SDE: Trypanotolerance in West African cattle and the population genetic effects of selection. In Ph.D. thesis University of Dublin; 200I.

18. Mosteller F, Fisher RA: Questions and answers. American Statistician 1948, 2:30-31.

19. Rice WR: Analysis tables of statistical tests. Evolution 1989, 43:223-225.

20. Weir BS, Cockerham CC: Estimating F-statistics for the analysis of population structure. Evolution 1984, 38: I 358-1370.

21. Goudet J: PCAGEN I.2. 2005.

22. Vähä JP, Erkinaro J, Niemela E, Primmer CR: Life-history and habitat features influence the within-river genetic structure of Atlantic salmon. Molecular Ecology 2007, I 6:2638-2654.

23. Evanno G, Regnaut S, Goudet J: Detecting the number of clusters of individuals using the software STRUCTURE: a simulation study. Molecular Ecology 2005, 14:26 II-2620.

24. Excoffier L, Laval G, Schneide S: Arlequin (version 3.0): An integrated software package for population genetics data analysis. Evolutionary Bioinformatics Online 2005, I:47-50.

25. Peakall R, Smouse PE: GENALEX 6: genetic analysis in Excel. Population genetic software for teaching and research. Molecular Ecology Notes 2006, 6:288-295.

26. Smouse PE, Long JC, Sokal RR: Multiple-regression and correlation extensions of the Mantel test of matrix correspondence. Systematic Zoology 1986, 35:627-632.

27. Distance calculations at Geoscience Australia [http://
] www.ga.gov.au/geodesy/datums/calcs.jsp]

28. Rousset F: Genetic differentiation and estimation of gene flow from F-statistics under isolation by distance. Genetics 1997, 145: $1219-1228$.
29. Hood GM: PopTools 2.7.5. Albany, Western Australia; 2006.

30. Hardy OJ, Charbonnel N, Freville H, Heuertz M: Microsatellite allele sizes: A simple test to assess their significance on genetic differentiation. Genetics 2003, I63:1467-| 482

31. Hardy OJ, Vekemans X: SPAGEDi: a versatile computer program to analyse spatial genetic structure at the individual or population levels. Molecular Ecology Notes 2002, 2:6 I 8-620.

32. Slatkin M: A Measure of Population Subdivision Based on Microsatellite Allele Frequencies. Genetics 1995, 139:457-462.

33. Petit RJ, El Mousadik A, Pons O: Identifying populations for conservation on the basis of genetic markers. Conservation Biology 1998, 1 2:844-855.

34. Petit R: Contrib V. I.02. 2006.

35. Kaukoranta M, Koljonen M-L, Koskiniemi J, Pennanen J, Tammi J: Atlas of Finnish fishes, English summary. Distribution of lamprey, brook lamprey, salmon, trout, Arctic charr, whitefish, vandace, grayling, asp, vimba, spined loach and bullhead, and status of the stocks. Finnish Game and Fisheries Research Institute, Helsinki, Finland; 2000:40.

36. Koskinen MT, Sundell P, Piironen J, Primmer CR: Genetic assessment of spatiotemporal evolutionary relationships and stocking effects in grayling (Thymallus thymallus, Salmonidae). Ecology Letters 2002, 5:193-205.

37. Gum B, Gross R, Rottmann O, Schroder W, Kuhn R: Microsatellite variation in Bavarian populations of European grayling (Thymallus thymallus): Implications for conservation. Conservation Genetics 2003, 4:659-672.

38. Moritz C: Defining evolutionarily-significant-units for conservation. Trends in Ecology \& Evolution 1994, 9:373-375.

39. Kristiansen $H$, Doving KB: The migration of spawning stocks of grayling Thymallus thymallus, in Lake Mjosa, Norway. Environmental Biology of Fishes 1996, 47:43-50.

40. Parkinson D, Philippart JC, Baras E: A preliminary investigation of spawning migrations of grayling in a small stream as determined by radio-tracking. Journal of Fish Biology 1999, 55: I72- I82.

4I. Heikkinen $\mathrm{O}$, Kurimo $\mathrm{H}$ : The postglacial history of Kitkajärvi, North-eastern Finland, as indicated by trend-surface analysis and radio-carbon dating. Fennia 1977, 153:1-32.

42. Vasemagi A, Gross R, Paaver T, Koljonen ML, Saisa M, Nilsson I: Analysis of gene associated tandem repeat markers in Atlantic salmon (Salmo salar L.) populations: implications for restoration and conservation in the Baltic Sea. Conservation Genetics 2005, 6:385-397.

43. Gross R, Lulla P, Naver T: Genetic variability and differentiation of rainbow trout (Oncorhynchus mykiss) strains in northern and Eastern Europe. Aquaculture 2007, 272:SI39-SI 46.

44. Fave MJ, Turgeon J: Patterns of genetic diversity in Great Lakes bloaters (Coregonus hoyi) with a view to future reintroduction in Lake Ontario. Conservation Genetics 2008, 9:28I-293.

45. Lehtonen PK, Tonteri A, Sendek D, Titov S, Primmer CR: Spatiotemporal genetic structuring of brown trout (Salmo trutta L.) populations within the River Luga, northwest Russia. Conservation Genetics 2009, 10:28I-289.

46. Hewitt GM: Post-glacial re-colonization of European biota. Biological Journal of the Linnean Society 1999, 68:87-I I2.

47. Hewitt GM: Genetic consequences of climatic oscillations in the Quaternary. Philos Trans R Soc Lond B Biol Sci 2004, 359( (1442): 183-195.

48. Susnik S, Berrebi P, Dovc P, Hansen MM, Snoj A: Genetic introgression between wild and stocked salmonids and the prospects for using molecular markers in population rehabilitation: the case of the Adriatic grayling (Thymallus thymallus L. 1785). Heredity 2004, 93:273-282.

49. Frankham R, Balou JD, Briscoe DA: Introduction to conservation genetics Cambridge, UK: Cambridge university press; 2002.

50. Crozier RH: Genetic diversity and the agony of choice. Biological Conservation 1992, 61: II-15.

51. Pertoldi C, Bijlsma R, Loeschcke V: Conservation genetics in a globally changing environment: present problems, paradoxes and future challenges. Biodiversity and Conservation 2007, 16:4147-4163.

52. Crandall KA, Bininda-Emonds ORP, Mace GM, Wayne RK: Considering evolutionary processes in conservation biology. Trends in Ecology \& Evolution 2000, 15:290-295. 